Fetal Diagnosis and Therapy
Fetal Diagn Ther 2017;42:204-209

DOI: $10.1159 / 000464323$
Received: February 1, 2017

Accepted: February 16, 2017

Published online: March 29, 2017

\title{
Impact of Laser Power and Firing Angle on Coagulation Efficiency in Laser Treatment for Twin-Twin Transfusion Syndrome: An ex vivo Placenta Study
}

\author{
Joost Akkermans $^{a} \quad$ Loes van der Donk ${ }^{b}$ Suzanne H.P. Peeters ${ }^{a}$ \\ Sjoerd van Tuijl ${ }^{b}$ Johanna M. Middeldorp ${ }^{a}$ Enrico Lopriore ${ }^{c}$ Dick Oepkes $^{a}$ \\ ${ }^{a}$ Department of Obstetrics, Leiden University Medical Center, Leiden, ${ }^{b}$ LifeTec Group, Eindhoven, and \\ 'Division of Neonatology, Department of Pediatrics, Leiden University Medical Center, Leiden, The Netherlands
}

\section{Keywords}

Twin-twin transfusion syndrome · Laser therapy · Laser power · Laser energy · Placenta

\begin{abstract}
Objective: To assess the impact of laser power and firing angle on coagulation efficiency for closing placental anastomoses in the treatment of twin-twin transfusion syndrome. Methods: We used an ex vivo blood-perfused human placenta model to compare time to complete coagulation using 30 vs. $50 \mathrm{~W}$ of neodymium-doped yttrium aluminum garnet laser power and using a firing angle of $90^{\circ} \mathrm{vs} .45^{\circ}$. Placentas were perfused with pig blood at $5 \mathrm{~mL} / \mathrm{min}$. Differences were analyzed using independent-samples $t$ test, MannWhitney U test, or $X^{2}$ test as appropriate. Results: Coagulation took less time and energy using $50 \mathrm{~W}(n=53)$ compared to $30 \mathrm{~W}(n=52), 11$ vs. $22 \mathrm{~s}(p<0.001)$, and $557 \mathrm{vs.} 659 \mathrm{~J}(p=$ $0.007)$. Perpendicular coagulation $(n=53)$ took less time and energy compared to a $45^{\circ}$ angle $(n=21), 11$ vs. $17 \mathrm{~s}$ ( $p=$ $0.004)$, and 557 vs. $871 \mathrm{~J}(p=0.004)$. Bleeding complicated 2 (3\%) measurements in the 50-W group, $5(10 \%)$ in the $30-W$ group, and $3(14 \%)$ in the $45^{\circ}$ group. Discussion: In a highly
\end{abstract}

\section{KARGER}

E-Mail karger@karger.com www.karger.com/fdt

\section{(C) 2017 The Author(s)}

Published by S. Karger AG, Basel

This article is licensed under the Creative Commons AttributionNonCommercial-NoDerivatives 4.0 International License (CC BYNC-ND) (http://www.karger.com/Services/OpenAccessLicense). Usage and distribution for commercial purposes as well as any distribution of modified material requires written permission. controlled model, a 50-W laser power setting was more energy efficient than $30 \mathrm{~W}$ in coagulating a placental vein. $\mathrm{A}$ more perpendicular laser firing angle resulted in more efficient coagulation. Furthermore, bleeding due to vessel wall disruption occurred more often with lower power and a more tangential approach.

(c) 2017 The Author(s)

Published by S. Karger AG, Basel

\section{Introduction}

Fetoscopic laser surgery is currently the best treatment modality for twin-twin transfusion syndrome (TTTS). De Lia et al. [1] first proposed fetoscopic laser surgery in 1990. In 2004, a randomized trial showed fetoscopic laser surgery to be superior to serial amnioreduction [2], and since then fetoscopic laser surgery has been widely adopted as the "first-choice" treatment for TTTS.

Different types of laser and power settings have been used for this procedure. Most centers now use either a neodymium-doped yttrium aluminum garnet (Nd:YAG) laser with a 1,064-nm wavelength or a diode laser with a 940-nm wavelength and a power setting between 20 and

Joost Akkermans, MD

Department of Obstetrics, Leiden University Medical Center PO Box 9600

NL-2300 RC Leiden (The Netherlands)

E-Mail j.akkermans@lumc.nl 
$80 \mathrm{~W}$ [3]. Both laser systems continuously emit laser energy with similar absorption properties. However, the optical penetration depth of the photons emitted by the diode laser is substantially lower than that of the Nd:YAG laser [4].

In 2014, Slaghekke et al. [5] showed that the Solomon technique, laser coagulation of the total vascular equator from one placenta margin to the other, was superior to the selective technique, where only visible anastomoses are coagulated, with respect to recurrence of TTTS and incidence of post-laser twin anemia-polycythemia sequence. With the Solomon technique, a larger surface area of the placenta is exposed to laser energy (time $\times$ power) and, in total, more energy is used during a procedure.

The laser firing angle is believed to be of importance for successful efficient coagulation [6]. The more perpendicular the laser fiber is pointed at the vessel, the faster coagulation is achieved. This is one of the reasons why choosing the optimal introduction site for the fetoscope is found to be one of the most important steps in the procedure [7]. However, the actual impact of a tangential approach has never been evaluated.

We hypothesized that faster, more efficient laser coagulation of placental vascular anastomoses would increase the safety and improve the outcome of the treatment of TTTS. This study is a first step in proving this hypothesis, aiming to analyze the impact of laser power and firing angle on coagulation efficiency.

\section{Methods}

\section{Study Design}

This ex vivo experimental human placenta study was conducted at the Department of Fetal Therapy of the Leiden University Medical Center between March and July 2015. After informed consent, term placentas from women with uncomplicated vaginal deliveries were obtained. Placentas were rinsed and stored at room temperature in a $0.9 \%$ sodium chloride solution directly after delivery. All experiments took place within $8 \mathrm{~h}$ after delivery of the placenta.

Three groups of measurements were performed comparing laser power setting and laser firing angle. Group 1 consisted of measurements perpendicular to the vein with a power setting of $50 \mathrm{~W}$. Group 2 consisted of measurements perpendicular to the vein with a $30-\mathrm{W}$ power setting. Group 3 consisted of measurements performed at a $45^{\circ}$ angle to the vein with a $50-\mathrm{W}$ power setting. All placentas were randomly assigned to these groups.

\section{Laser System}

A Medilas Fibertom 5100 Nd:YAG laser (Dornier MedTech Europe $\mathrm{GmbH}$, Weßling, Germany) with a 1,064-nm wavelength was used for all experiments. A $600-\mu \mathrm{m}$ bare-tip laser fiber was used which was replaced after every 25 measurements. The laser was serviced and calibrated before the study was started.
Tissue Preparation

All placentas were screened for eligible veins with a diameter of approximately $1.5-2.0 \mathrm{~mm}$, relatively straight and without branches over a length of $2 \mathrm{~cm}$. These vessels were dissected on both ends and cannulated with a $1.4-\mathrm{mm}$ plastic cannula. The cannula was kept in place with a surgical stitch. The placenta samples were cast in $12-\mathrm{cm}$ petri dishes filled with $2 \%$ agar solution (Sigma-Aldrich Chemie B.V., Zwijndrecht, The Netherlands) with the maternal side downward, a layer of agar preventing the placenta to touch the bottom of the petri dish. The adhesive character of the agar solution prevented leakage from minor defects of the basal plate. A high-definition photograph of each cannulated vessel was taken. All vessel diameters were measured using the ImageJ $1.47 \mathrm{v}$ software (ImageJ, National Institutes of Health, Bethesda, MD, USA).

\section{Experimental Setup}

A diagram of the experimental setup is given in Figure 1. The placenta samples were placed in a $0.9 \%$ sodium chloride bath and kept at a steady temperature of $37^{\circ} \mathrm{C}$. The cannulated vein was connected to the circulation system that consisted of a calibrated syringe pump (Fresenius-Kabi Pilot C, Zeist, The Netherlands) with $\pm 2 \%$ flow rate accuracy, connected to a P10EZ-1 pressure sensor (Becton Dickinson Medical, Franklin Lakes, NJ, USA) and a flow sensor (Transonic clamp-on 2 pxl flow sensor with a Transonic TS410 amplifier).

The laser fiber was kept in place by a system that allowed for easy and accurate adjustment, and was pointed either perpendicular or at a $45^{\circ}$ angle at the vein. The distance between the laser fiber tip and the vein was kept at $4.0 \mathrm{~mm}$ for each experiment.

Fresh heparinized $(5,000 \mathrm{IU} / \mathrm{L})$ pig blood with a temperature of $37^{\circ} \mathrm{C}$ was used to circulate through the placental vein. The flow rate was set at $5 \mathrm{~mL} / \mathrm{min}$. The entire circulation was checked for leaks before each experiment.

A computer program continuously measured the flow and the pressure in the circulation and the mode of the laser system (on/ off). The results of these measurements were plotted on a screen in real time. Measurements started when the laser was activated and continued until successful coagulation of the vein was achieved. Successful coagulation was defined by a drop of the flow speed below $2.5 \mathrm{~mL} / \mathrm{min}$ without recovery. The noise on the flow sensor signal combined with the already low flow prevented us from using a flow of $0 \mathrm{~mL} / \mathrm{min}$ to define stagnation of flow. Time was automatically measured between activation of the laser and stagnation of flow. Concurrently, the total energy used in each experiment was calculated based on the power setting.

\section{Statistical Analysis}

Comparisons were made between group 1 and group 2 as well as between group 1 and group 3 with respect to the time and energy used for successful coagulation defined as cessation of flow. Cases complicated by vessel wall disruption and bleeding were omitted from the analyses. Analyses were conducted using IBM SPSS Statistics for Windows, version 22.0, released 2013 (IBM Corp., Armonk, NY, USA). Normally distributed data were expressed as mean \pm standard deviation (SD) and compared using an independent-samples $t$ test. Skewed data were expressed as median with range and were compared using a Mann-Whitney U test. For comparison of categorical data, a $\chi^{2}$ test was used. A $p$ value $<0.05$ was considered statistically significant.
Ex vivo Analysis of Laser Power and

Angle for Coagulation of Placental Vessels
Fetal Diagn Ther 2017;42:204-209

DOI: $10.1159 / 000464323$
205 


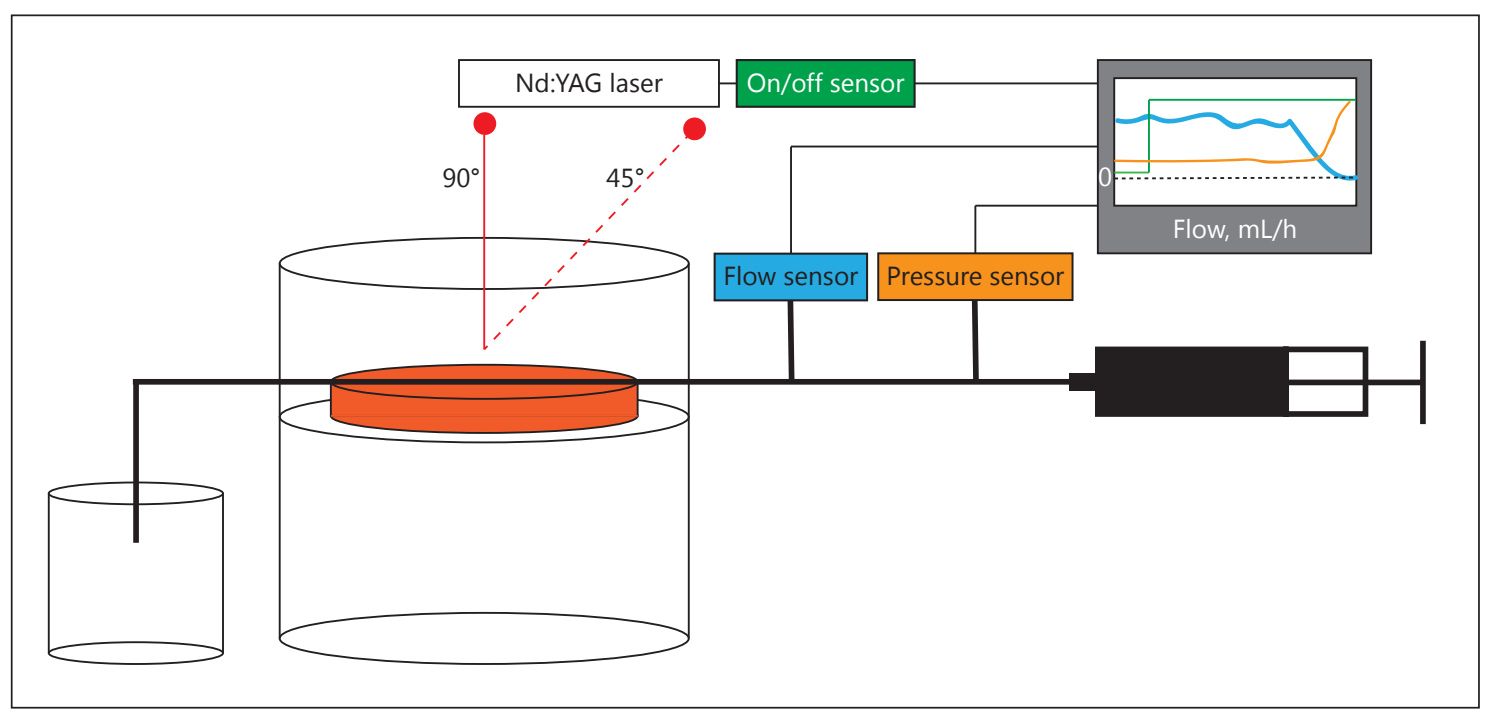

Fig. 1. Diagram of the experimental setup.
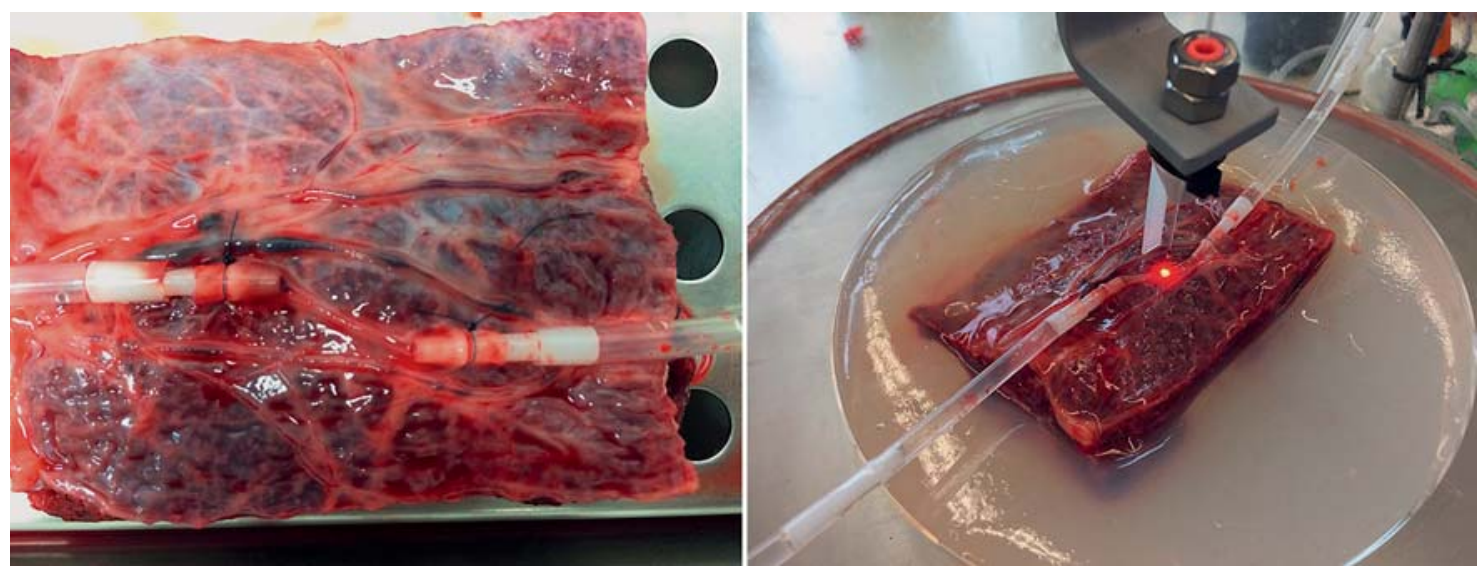

Fig. 2. Photograph of a sample before and during laser coagulation.

\section{Results}

Out of 37 fresh human placentas, a total of 126 viable samples were retrieved. Overall 126 measurements were conducted, and successful coagulation was achieved in 116 samples. All results and comparisons between groups are shown in Table 1. Figure 2 shows a sample before and during successful coagulation.

\section{Group 1}

In total, 53 measurements were performed perpendicular to the vein with a $50-\mathrm{W}$ laser power setting. In 2 samples (4\%), bleeding occurred during coagulation, and in 1 of these successful coagulation was achieved. Fiftyone cases were eligible for analysis. The mean vessel diameter was $1.60 \pm 0.14 \mathrm{~mm}$ and the median time needed for cessation of flow in the vein was $11.1 \mathrm{~s}(1.4-32.8)$, which led to a median energy used of $557 \mathrm{~J}(72-1,639)$.

\section{Group 2}

Fifty-two measurements were performed perpendicular to the vein at a power of $30 \mathrm{~W}$. Five cases $(10 \%)$ were complicated by bleeding, and in 2 cases successful coagulation could not be achieved. Forty-seven cases were analyzed. The mean vessel diameter in this group was $1.6 \pm$ $0.12 \mathrm{~mm}$ and the median coagulation time was $22.0 \mathrm{~s}$ 
Table 1. Analysis of laser duration and total energy for each group

\begin{tabular}{|c|c|c|c|c|c|}
\hline & $\begin{array}{l}\text { Group } 1,50 \mathrm{~W} 90^{\circ} \\
(n=53)\end{array}$ & $\begin{array}{l}\text { Group } 2,30 \mathrm{~W} 90^{\circ} \\
(n=52)\end{array}$ & $\begin{array}{l}\text { Group } 3,50 \mathrm{~W} 45^{\circ} \\
(n=21)\end{array}$ & $\begin{array}{l}p \text { value } 1 \\
\text { versus } 2\end{array}$ & $\begin{array}{l}p \text { value } 1 \\
\text { versus } 3\end{array}$ \\
\hline Laser duration, s & $11.13(1.43-32.77)$ & $21.98(8.49-314.39)$ & $17.42(2.64-78.13)$ & $<0.001^{*}$ & $0.004^{*}$ \\
\hline Laser energy used, J & $556.50(71.50-1,638.50)$ & $659.40(254.70-9,431.70)$ & $871.25(132.00-3,906.50)$ & $0.007^{*}$ & $0.004^{*}$ \\
\hline Vein diameter, $\mathrm{mm}$ & $1.61 \pm 0.14$ & $1.63 \pm 0.12$ & $1.65 \pm 0.12$ & 0.347 & 0.223 \\
\hline Complications, bleeding & $2(3 \%)$ & $5(10 \%)$ & $3(14 \%)$ & $0.116^{* *}$ & $0.104^{* *}$ \\
\hline
\end{tabular}

Values are expressed as median (range), mean $\pm \mathrm{SD}$, or $n(\%)$. All cases where bleeding occurred were excluded from the analyses. * Mann-Whitney U test. ${ }^{* *} \chi^{2}$ test.

(8.5-314.4). The median energy used for coagulation was $659 \mathrm{~J}(254-9,431)$.

\section{Group 3}

Using 50-W laser power at an angle of $45^{\circ}, 21$ measurements were performed. Three samples (14\%) were complicated by vessel wall disruption, and in none of these successful coagulation could be accomplished. The mean vessel diameter was $1.65 \pm 0.12 \mathrm{~mm}$ and the median time for coagulation was $17.4 \mathrm{~s}(2.6-78.1)$, leading to a median total energy used of $871 \mathrm{~J}(132-3,906)$.

Coagulation took significantly less time and energy using $50-\mathrm{W}$ compared to $30-\mathrm{W}$ laser (11.1 vs. $21.0 \mathrm{~s}, p<$ 0.001 , and 556 vs. $659 \mathrm{~J}, p=0.007)$. Perpendicular coagulation took significantly less time and energy compared to a $45^{\circ}$ angle ( 11.1 vs. $17.4 \mathrm{~s}, p=0.004$, and 556 vs. $871 \mathrm{~J}$, $p=0.004)$. The vessel diameter did not differ between the 50 - and $30-\mathrm{W}$ samples (1.6 vs. $1.6, p=0.347$ ) or between the $90^{\circ}$ and $45^{\circ}$ samples ( 1.6 vs. $1.6 \mathrm{~mm}, p=0.223$ ).

\section{Discussion}

This is the first study reporting on an ex vivo perfused human placenta model to evaluate laser coagulation efficiency of different power settings for obliterating superficial placental vessels. To date, despite more than 25 years of laser surgery for TTTS, the ideal power setting for coagulation of anastomosis is unknown. Different strategies are being used, e.g. lower power setting at early gestational age at treatment or power setting depending on the size of the anastomosis [3].

In this study, we found that a higher power setting was associated with more efficient coagulation, shown by a shorter coagulation time and less energy used. In addition, we found that the firing angle significantly impacts the coagulation efficiency. A $45^{\circ}$ angle almost doubles the

Ex vivo Analysis of Laser Power and Angle for Coagulation of Placental Vessels amount of energy and time needed for successful coagulation compared to a perpendicular approach. With currently used equipment, optimization of the angle of approach can only be achieved by careful selection of the site of entry of the fetoscope. Innovations in instrument design may be needed to optimize the efficiency of laser coagulation in difficult cases with anterior placenta or suboptimal position of the donor.

Bleeding due to vessel wall disruption, although rare, occurred slightly more often with lower power settings and with a more tangential laser angle. We hypothesize that a low power setting used for a longer period of time causes more endothelium damage [8], and without swift occlusion of the vessel by coagulated blood, this might increase the risk of vessel wall disruption and bleeding.

Recently, Zhao et al. [9] showed that, after a laser procedure, more chorioamnionitis and funisitis is seen compared to nonlasered monochorionic twin pregnancies. A possible explanation for this finding is the iatrogenic placental tissue necrosis caused by laser coagulation that may induce a maternal inflammatory response. In their study, a trend was seen towards more chorioamnionitis with higher energy use $(p=0.06)$. A previous study looked at the impact of laser coagulation on the ovine placenta with respect to local, collateral, and peripheral damage at different time points after treatment [10]. This study showed that the tissue effect, especially collateral and peripheral, increases over time. Superficial vessel coagulation induced complete functional elimination of the involved cotyledon caused either by direct tissue damage and/or by arrest of the cotyledonary flow, leading to ischemic necrosis. In this study, the impact of the amount of energy delivered and the relationship to tissue damage was not reported. A study evaluating different Nd:YAG power settings for the cutting and coagulation of pulmonary parenchyma with interstitial laser found that reducing the exposure time reduces local tissue coagulation

Fetal Diagn Ther 2017;42:204-209 DOI: $10.1159 / 000464323$ 
even when the laser power output is increased [11]. Combining our results with previous research suggests that efficiency in the use of laser energy for laser treatment of TTTS might be beneficial and that a higher power setting and a perpendicular approach are more energy efficient, and safer, in attaining successful coagulation.

Although the highly realistic ex vivo human placenta model we used eliminated many confounding factors, some limitations exist. The most important limitations of the model are the flow rate and the resistance of the circulation. It is difficult to accurately measure and control flow at flow rates $<5 \mathrm{~mL} / \mathrm{min}$ in a model. Not much is known about single anastomotic blood flow rates. Two studies reporting on anastomotic blood flow showed very different results, between $11.6 \mathrm{~mL} / \mathrm{min}$ with intra-amniotic Doppler measurements [12] and $5.6 \mathrm{~mL} / 24 \mathrm{~h}$ based on calculation of decreasing hemoglobin levels between intrauterine transfusion and birth [13]. The first one being highly unlikely due to the fact that the amount of flow exceeds the total blood volume of a midgestation fetus, currently no reliable technique exists to assess single anastomotic blood flow. The higher flow rate used in this model, compared to true TTTS anastomotic flow, leads to longer coagulation time due to the heat sink phenomenon, i.e. constant dissipation of laser energy caused by blood flow from the coagulation site.

Also, a higher flow rate may result in higher pressure buildup during coagulation, leading to a higher incidence of vessel wall disruption compared to in vivo coagulation of anastomoses in TTTS. Furthermore, the model uses pig blood instead of human blood, although this is similar to human blood with respect to size of red blood cells, red blood cell life span, and hemoglobin content and structure [14]. The consequence of these limitations is that time and energy results may not exactly correspond to reality. However, the use of the model ensures that all measurements are performed under constant conditions. We do not expect the limitations mentioned to have influenced the effect we showed.
Future studies using the model will focus on using diode laser and multiple power settings to identify the optimal power setting for different anastomosis types and sizes.

\section{Conclusion}

This study demonstrates that in a highly controlled though realistic environment, a $50-\mathrm{W}$ laser power setting is more efficient in coagulating a placental vein with respect to time and total energy needed compared to a 30-W laser power setting. In addition, we showed that the firing angle of the laser has a great impact on coagulation efficiency. The more perpendicular the approach, the more efficient the coagulation achieved.

\section{Acknowledgment}

This research was supported by the Dutch Technology Foundation (STW), which is part of the Netherlands Organization for Scientific Research (NWO) and which is partly funded by the Ministry of Economic Affairs.

\section{Statement of Ethics}

The protocol of this study was screened by our local ethics committee and found not to fall under the scope of the Dutch WMO (Medical Research Involving Human Subjects Act), since placentas were obtained after informed consent and could not be traced back to the mother. For the experiments, fresh pig blood obtained from a licensed slaughterhouse was used. All experiments were conducted conformed with the institutional standards regarding human and animal tissue.

\section{Disclosure Statement}

None of the authors have any conflict of interest.
References

208
1 De Lia JE, Cruikshank DP, Keye WR Jr: Fetoscopic neodymium:YAG laser occlusion of placental vessels in severe twin-twin transfusion syndrome. Obstet Gynecol 1990;75: 1046-1053.

2 Senat MV, Deprest J, Boulvain M, Paupe A, Winer N, Ville Y: Endoscopic laser surgery versus serial amnioreduction for severe twinto-twin transfusion syndrome. $\mathrm{N}$ Engl J Med 2004;351:136-144.
3 Akkermans J, Peeters SH, Middeldorp JM, Klumper FJ, Lopriore E, Ryan G, Oepkes D: A worldwide survey of laser surgery for twintwin transfusion syndrome. Ultrasound $\mathrm{Ob}$ stet Gynecol 2015;45:168-174.

4 Berlien HP, Breuer H, Müller GJ, Krasner N, Okunata T, Sliney D: Applied Laser Medicine. Berlin/Heidelberg, Springer, 2003, pp 408423.
Akkermans/van der Donk/Peeters/ van Tuijl/Middeldorp/Lopriore/Oepkes 
5 Slaghekke F, Lopriore E, Lewi L, Middeldorp JM, van Zwet EW, Weingertner AS, Klumper FJ, DeKoninck P, Devlieger R, Kilby MD, Rustico MA, Deprest J, Favre R, Oepkes D: Fetoscopic laser coagulation of the vascular equator versus selective coagulation for twinto-twin transfusion syndrome: an open-label randomised controlled trial. Lancet 2014;383: 2144-2151.

6 Van Peborgh P, Rambaud C, Ville Y: Effect of laser coagulation on placental vessels: histological aspects. Fetal Diagn Ther 1997;12:3235.

7 Peeters SH, Akkermans J, Westra M, Lopriore E, Middeldorp JM, Klumper FJ, Lewi L, Devlieger R, Deprest J, Kontopoulos EV, Quintero R, Chmait RH, Smoleniec JS, Otano L, Oepkes D: Identification of essential steps in laser procedure for twin-twin transfusion syndrome using the Delphi methodology: SILICONE study. Ultrasound Obstet Gynecol 2015;45:439-446.
8 Nizard J, Barbet JP, Ville Y: Does the source of laser energy influence the coagulation of chorionic plate vessels? Comparison of Nd:YAG and diode laser on an ex vivo placental model. Fetal Diagn Ther 2007;22:33-37.

9 Zhao D, Cohen D, Middeldorp JM, van Zwet EW, De Paepe ME, Oepkes D, Lopriore E: Histologic chorioamnionitis and funisitis after laser surgery for twin-twin transfusion syndrome. Obstet Gynecol 2016;128:304312.

10 Branisteanu-Dumitrascu I, Deprest JA, Evrard VA, van Ballaer PP, van Schoubroeck D, Gratacos E, Pijnenborg R: Time-related cotyledonary effects of laser coagulation of superficial chorionic vessels in an ovine model. Prenat Diagn 1999;19:205-210.
11 Kirschbaum A, Palade E, Kayser G, Passlick B: Local effects of high-powered neodymiumdoped yttrium aluminium garnet laser systems on the pulmonary parenchyma: an experimental study on the isolated perfused pig lung lobe. Interact Cardiovasc Thorac Surg 2012;15:191-193.

12 Nakata M, Martinez JM, Diaz C, Chmait R, Quintero RA: Intra-amniotic Doppler measurement of blood flow in placental vascular anastomoses in twin-twin transfusion syndrome. Ultrasound Obstet Gynecol 2004;24: 102-103.

13 Lopriore E, van den Wijngaard JP, Middeldorp JM, Oepkes D, Walther FJ, van Gemert MJ, Vandenbussche FP: Assessment of fetofetal transfusion flow through placental arterio-venous anastomoses in a unique case of twin-to-twin transfusion syndrome. Placenta 2007;28:209-211.

14 Cooper DK, Hara H, Yazer M: Genetically engineered pigs as a source for clinical red blood cell transfusion. Clin Lab Med 2010;30:365380 .
Ex vivo Analysis of Laser Power and Angle for Coagulation of Placental Vessels
Fetal Diagn Ther 2017;42:204-209

DOI: $10.1159 / 000464323$ 